\title{
Corrigendum
}

\section{Reactions of three [c]annelated 2-aminothiophenes with electron poor olefins}

\author{
E. Sopbué Fondjo ${ }^{\text {a,* }}$ and D. Döpp \\ ${ }^{a}$ Laboratory of Applied Synthetic Organic Chemistry,Department of Chemistry, Faculty of \\ Sciences, University of Dschang, P.O.Box 067 Dschang, Republic of Cameroon \\ E-mail:sopbue@yahoo.fr \\ ${ }^{b}$ Organische Chemie, Universität Duisburg-Essen, 47057 Duisburg, Germany \\ E-mail:doepp@uni-duisburg.de
}

ARKIVOC 2006 (x), pp 90-101

On page 91, Scheme 1, eqn. (2) should read:

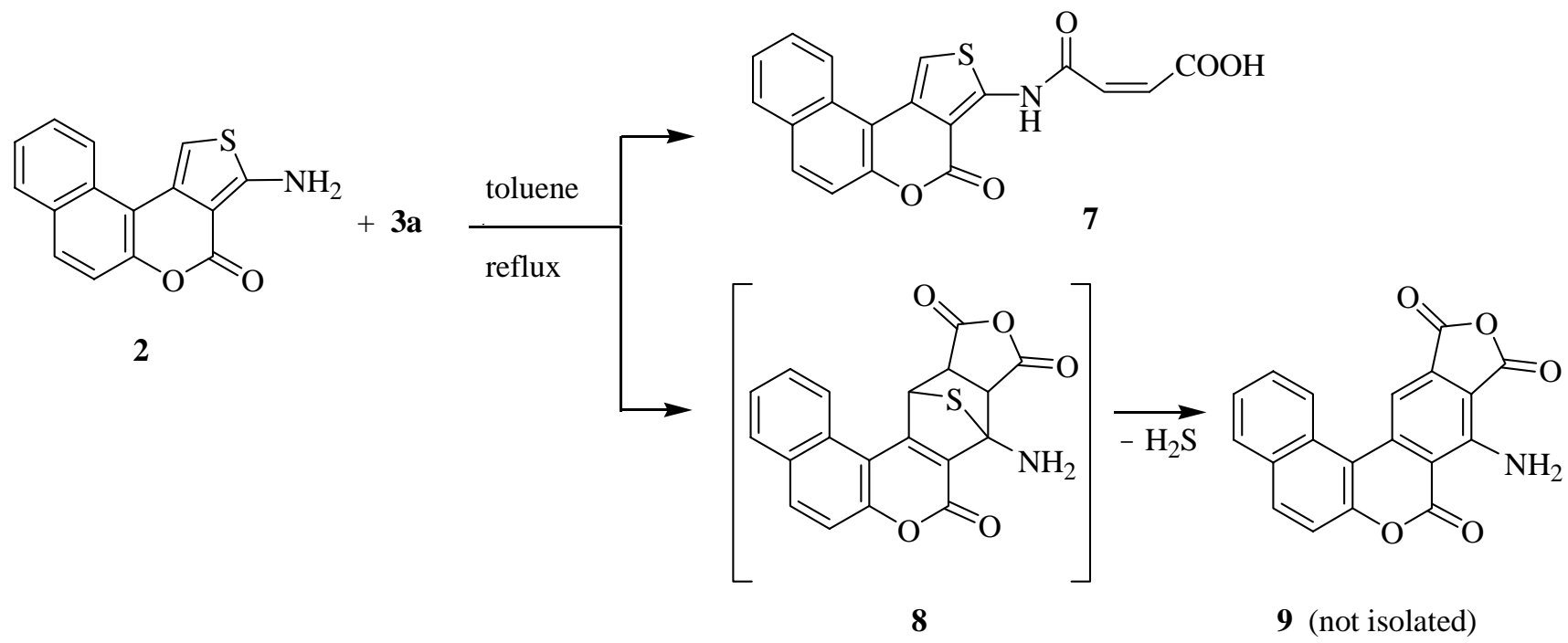

Thus, structure 9 in the original version has to be withdrawn.

Consequently, the bottom paragraph on p 91 should read:

From the reaction of substrate $\mathbf{2}$ with $\mathbf{3 a}$ in refluxing toluene, the maleamic acid $\mathbf{7}$ was obtained. The mother liquor contained a further crop of $\mathbf{7}$ and a minor quantity of the anhydride $\mathbf{9}$ (as identified by ${ }^{1} \mathrm{H}$ NMR) originating from the labile byproduct 8 . 
And on p 96, lines 21-23 should read:

The mother liquor was concentrated to dryness under reduced pressure. The solid residue was crystallized from toluene to afford $461 \mathrm{mg}$ of a mixture of at least two compounds. One third of that mixture (20\% by ${ }^{1} \mathrm{H}$ NMR integration, based on starting material 2 used) was proved to be $\mathbf{7}$, and the remaining material consisted largely of $\mathbf{9}$ as assigned by ${ }^{1} \mathrm{H}$ NMR analysis. 